\title{
Colored or Transparent Orthodontic Ligatures, Which One Has the Best Performance?
}

\author{
Glaucio Serra Guimarães ${ }^{1 *}$, Julio Pedra e Cal Neto ${ }^{1}$, Camilla Vannier ${ }^{2}$, Vanessa Mazza ${ }^{2}$, Jéssica \\ Duarte de Souza $^{2}$ and Luciana Rougemont Squeff ${ }^{3}$ \\ ${ }^{1}$ Associate Professor, Division of Orthodontics, School of Dentistry, Federal Fluminense University at Nova Friburgo, Rio de \\ Janeiro, Brazil
}

${ }^{2}$ Undergraduate Student, School of Dentistry, Federal Fluminense University at Nova Friburgo, Rio de Janeiro, Brazil

${ }^{3}$ Professor, Division of Orthodontics, School of Dentistry, Federal Fluminense University at Nova Friburgo, Rio de Janeiro, Brazil

*Corresponding author: Glaucio Serra Guimarães, Associate Professor, Division of Orthodontics, School of Dentistry,

Federal Fluminense University at Nova Friburgo, Rio de Janeiro, Brazil

\begin{tabular}{|c|c|}
\hline ARTICLE INFO & ABSTRACT \\
\hline Received: 慧 September 01, 2020 & Citation: Glaucio Serra Guimarães, Julio Pedra e Cal Neto, Camilla Vannier, Vanessa Mazza, \\
\hline Published: 豐 September 09, 2020 & $\begin{array}{l}\text { Jéssica Duarte de Souza, Luciana Rougemont Squeff. Colored or Transparent Orthodontic } \\
\text { Ligatures, Which One Has the Best Performance?. Biomed J Sci \& Tech Res 30(2)-2020. } \\
\text { BJSTR. MS.ID.004916. }\end{array}$ \\
\hline
\end{tabular}

\section{Introduction}

The demand for orthodontic treatment by adults has been increasingly significant. This trend is accompanied by an increased search for aesthetic devices in order to make them less noticeable during treatment[1,2]. Transparent aligners and monocrystalline ceramic brackets have been increasingly chosen by adult patients 3 .

Orthodontic treatments with ceramic brackets have their weak point, under the aesthetic aspect, in the transparent elastics, since the brackets are resistant to discoloration while the elastics are easily pigmented with the influence of the diet, significantly compromising the aesthetics of the orthodontic system1,4. Orthodontic ligatures are elastomeric polymers and consist of materials that, after substantial physical deformation, quickly return to its original dimensions[5-8]. They are amorphous polymers of high molecular weight that presents physical properties such as visco-elasticity, creep and stress relaxation[9,10]. With the advent of vulcanization, the use for elastic polymers in adverse conditions greatly increased $[7,11]$. This process makes the end product more resistant and efficient in the oral environment use[9].

Orthodontic elastomeric ligatures are polyurethanes whose exact composition is a particular formulation of each commercial brand $[5,12,13]$. Polyurethane is a generic term given to elastic polymers that contain the urethane linkage. They are not direct polymers of urethane but are synthesized through a process of reactions of either polyesters or polyether's with isocyanides to produce a complex structure with urethane. The advantages of this material are that they are easily applied, do not bother the patient, and have a variety of colors, but they are not ideal materials[14,15]. The mainly clinical disadvantages are the force relaxation, friction, color change, microbial retention, and the less fixation effectiveness compared to steel ligatures and self-ligation brackets[11,16,17]. The appearance and properties may also be affected when exposed to common factors presents in the Orthodontic use such as continuum deformation force, intra-oral fluids, food contact, oral enzymes, abrupt temperature variation, and light exposition during the storage[18-20]. The quality of the final product will define the function to transform the elastic potential energy into mechanical energy in the tooth movement[21].

It depends crucially on the technology of the manufacturing process[22,23]. So, the clinical performance is the resulting level of quality of raw material used, technology, and refinement of the production technique[14,24]. By the chemical structure view, the 
force transmitted by the stretched polymer depends, among others, on the degree of compression of the polymer mass, the strength of the covalent bonds and the intensity of the intermolecular forces, which are directly related to the molecular composition[8]. The different colors of the orthodontic elastics are obtained by adding dyes to the polymeric composition. The change in the polymer composition by the addition of color pigments can be a possible factor to modify the initial effectiveness tie and degradation, compromising its functionality[3]. Thus, the aim of this study was to evaluate the color influence in the initial orthodontic ligature effectiveness through the simulation of first-order bend in a tensile test. The null hypothesis for this study is that there would be no significant difference in initial force of color and crystal orthodontic elastomeric ligatures.

\section{Materials and Methods}

The present study was conducted to investigate the effect of the color in initial tie effectiveness of the elastomeric ligatures. The laboratorial tests used a total of 360 elastomeric ligatures samples, in gray and crystal colors, from three commercial brands. In order to obtain the first-order bend simulation, a device was produced consisting in a rectangular acrylic block fixed to an acrylic plate and an upper central incisor bracket (Twin-Edge ${ }^{\circledR} 0,022$ "x 0,028"-inch, Edgewise Standard; TP Orthodontics, New Buffalo, USA) was fixed to the block with its base parallel to the base of the acrylic plate. Another device was used consisting of two stainless steel hooks $11 \mathrm{~mm}$ distant from each other, joined by a welded sidebar, keeping perfect alignment and leveling. To set up the mechanism and ensure the correct alignment for the tension measurements, the acrylic device was fixed on the base of the universal testing machine (EMIC DL 2000, São José dos Pinhais, Brazil) and the hooks were attached to the superior axis of the machine.

The ligatures were fixed to the bracket with orthodontic stainless-steel wire 0.019 "x 0.025 "-inch (TP Orthodontics, New Buffalo, USA) and the hooks were fit to the orthodontic wire. The tests were performed with the mechanical traction on the vertical axis of the universal testing machine in magnitudes of $0.5,1.0$, and $1.5 \mathrm{~mm}$ resulting in the first-order bends simulation (Figure 1). In each tension test, the universal testing machine was equipped with a 50-N load cell and the tests were performed in room temperature by applying a rate of $2 \mathrm{~mm}$ per minute[21]. Six groups of samples were tested in tension magnitudes of $0.5,1.0$, and $1.5 \mathrm{~mm}$ (Figure 2). Each group was composed by 20 elastomeric ligature samples in gray and crystal colors from 3 commercial brands (3M Unitek, Morelli and Uniden). The statistical analysis was applied in order to compare the crystal and gray elastics in each brand. Descriptive statistics including mean, standard deviation, minimum and maximum values were calculated for each group tested. The Shapiro-Wilk test was applied to confirm the normal distribution of the groups. The statistical confrontation between gray and crystal elastics was obtained by applying the unpaired $T$ test for each brand and each tension magnitude $(\mathrm{P}<.05)$. (Graph Pad Prisma Software, v.8.3.1, San Diego, Ca).

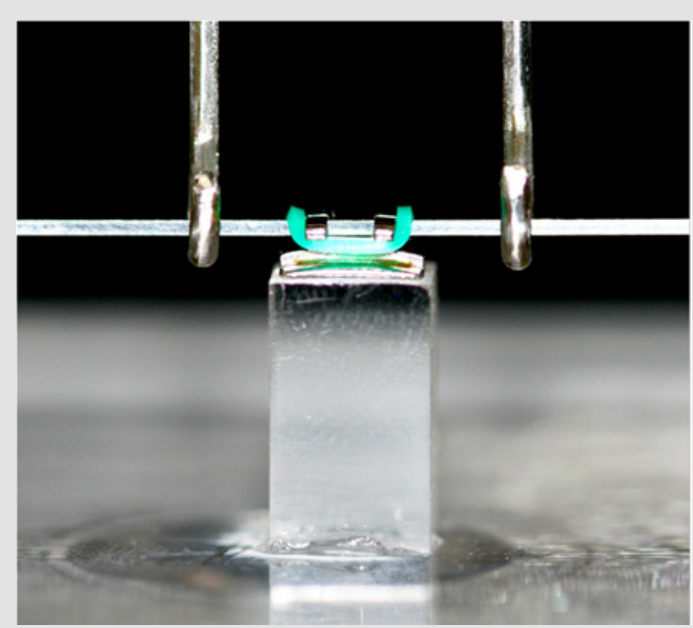

Figure 1: Experimental in vitro model of first-order bend tensile test in vertical view.

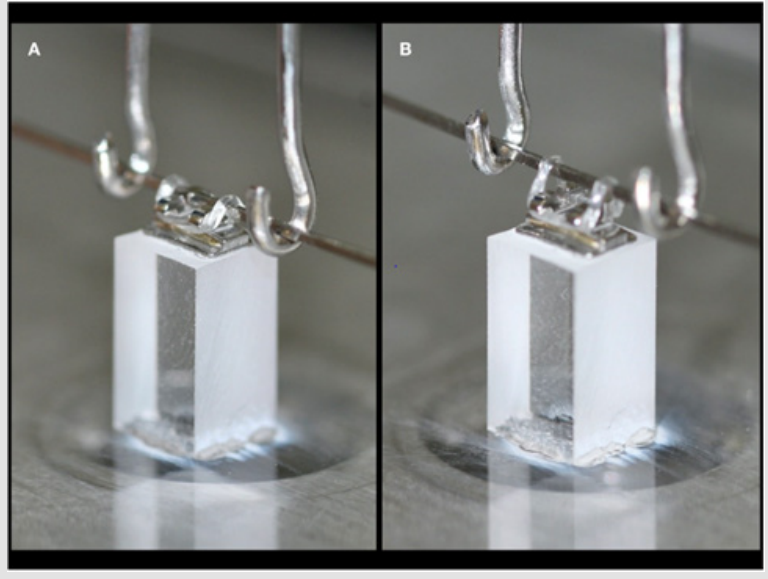

Figure 2: Tensile Test Magnitudes: A: 0,5 mm; B: 1,5 mm.

\section{Results}

The orthodontic traction test showed, in all the confrontations between crystal and gray groups, similar comparative results in the three magnitudes. Measurements increased with increased stretch, as expected. Therefore, the greater the intensity of the first order bending simulation, the greater the force transmitted by the elastics.When the gray and crystal elastics were compared in each commercial brand in the $0.5 \mathrm{~mm}$ magnitude, gray showed greater fixation efficiency than the crystal in all commercial brands. The most significant statistical difference was in the Unitek M group $(\mathrm{P}<0.05)$ (Table 1).When the elastics were analyzed at the $1.0 \mathrm{~mm}$ traction magnitude, the crystal elastics again showed less resistance to fixation and the higher statistical difference was among the $3 \mathrm{M}$ Unitek elastics (Table 2).The pattern was maintained when the elastics were tested with a tension magnitude of $1.5 \mathrm{~mm}$, in which the gray elastics presented a fixation force statistically greater than the crystal-colored elastics (Table 3). 
Table 1: Descriptive statistics, parametric t test results and graph showing the median, minimum and maximum values for the 0.5 $\mathrm{mm}$ tensile test $(\mathrm{N})$ for the gray and crystal ligatures of 3 comercial brands (3M, Morelli and Uniden) (N 20).

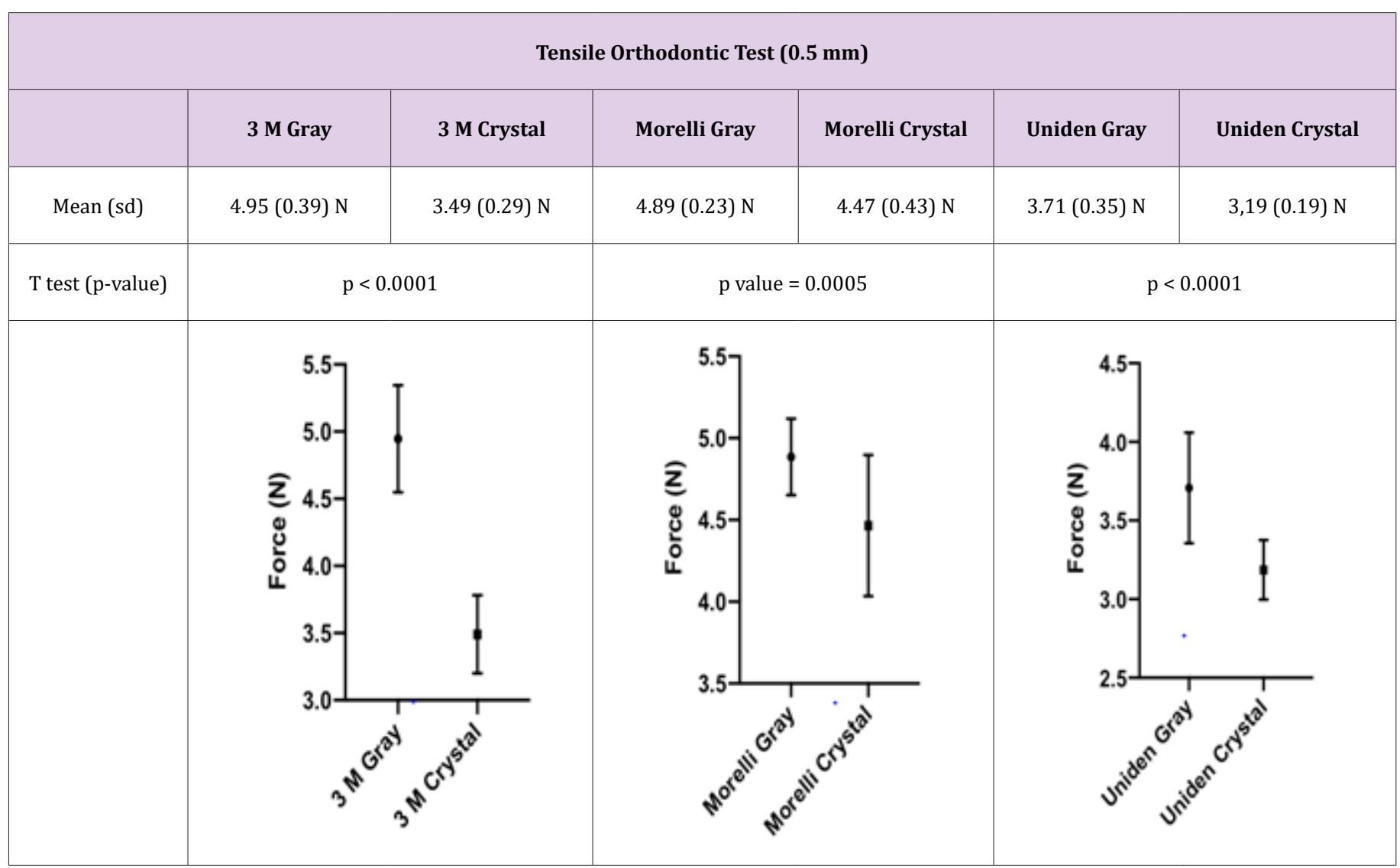

Table 2: Descriptive statistics, parametric t test results and graph showing the median, minimum and maximum values for the 1.0 $\mathrm{mm}$ tensile test $(\mathrm{N})$ for the gray and crystal ligatures of 3 comercial brands (3M, Morelli and Uniden) (N 20).

Tensile Orthodontic Test $(1.0 \mathrm{~mm})$

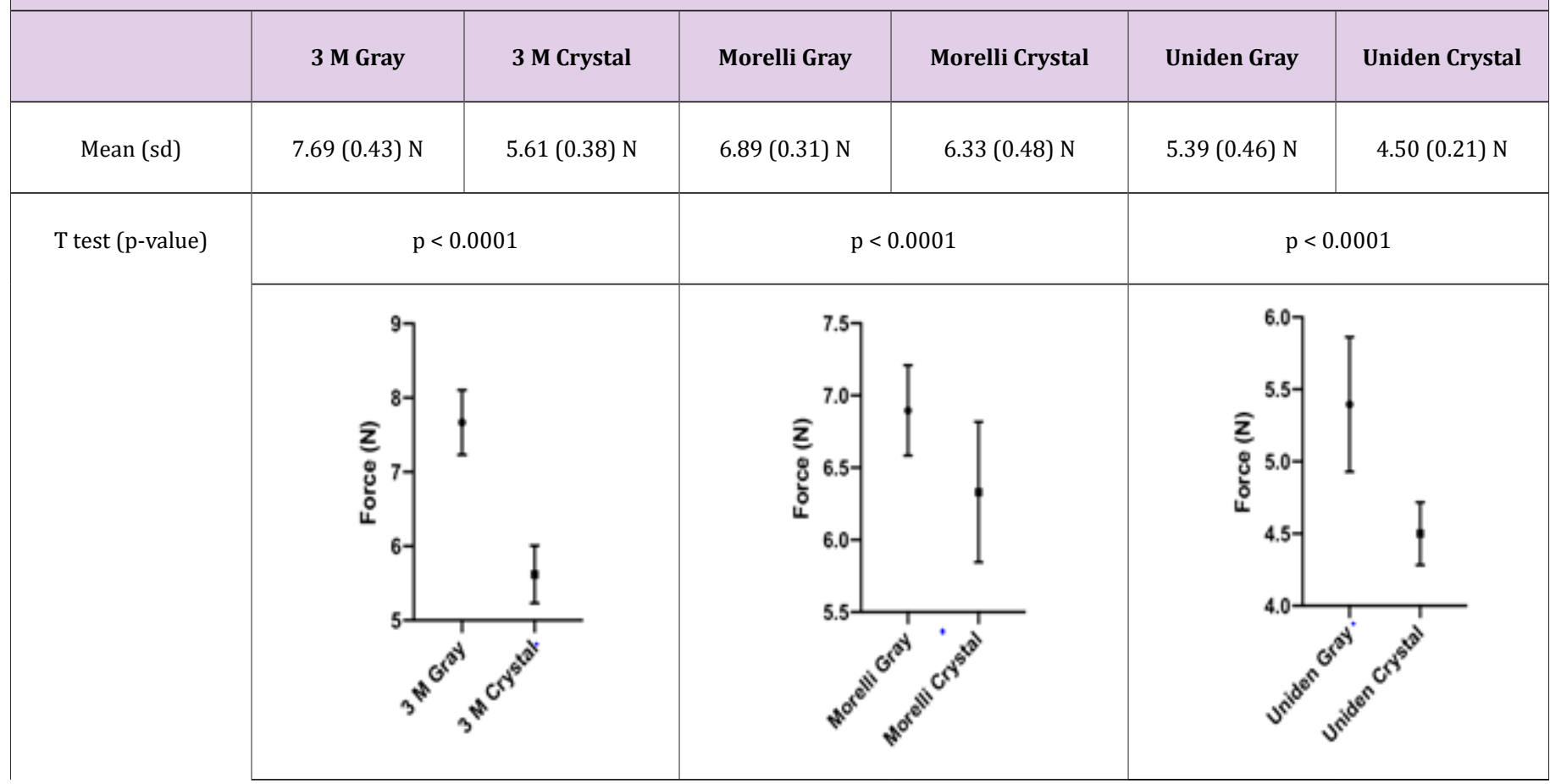


Table 3: Descriptive statistics, parametric t test results and graph showing the median, minimum and maximum values for the 1.5 $\mathrm{mm}$ tensile test $(\mathrm{N})$ for the gray and crystal ligatures of 3 comercial brands (3M, Morelli and Uniden) (N 20).

\begin{tabular}{|c|c|c|c|c|c|c|}
\hline \multicolumn{7}{|c|}{ Tensile Orthodontic Test (1.5 mm) } \\
\hline & 3 M Gray & 3 M Crystal & Morelli Gray & Morelli Crystal & Uniden Gray & Uniden Crystal \\
\hline Mean (sd) & $11.00(0.62) \mathrm{N}$ & $7.84(0.65) \mathrm{N}$ & $8.92(0.46) \mathrm{N}$ & $8.13(0.57) \mathrm{N}$ & $7,10(0.60) \mathrm{N}$ & $5,85(0.25) \mathrm{N}$ \\
\hline$T$ test (p-value) & \multicolumn{2}{|c|}{$\mathrm{p}<0.0001$} & \multicolumn{2}{|c|}{$\mathrm{p}<0.0001$} & \multicolumn{2}{|c|}{$\mathrm{p}<0.0001$} \\
\hline & 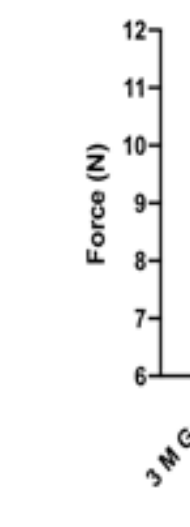 & $I$ & 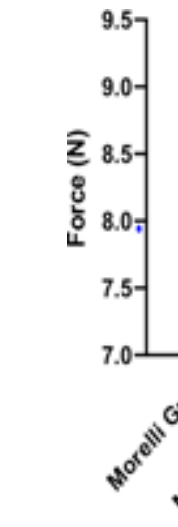 & 1 & 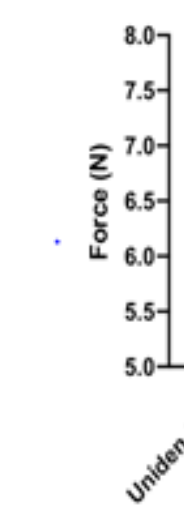 & $\frac{I}{9}$ \\
\hline
\end{tabular}

\section{Discussion}

The including of dyes on the composition of the ligatures has two main objectives: to produce a large variety of colors and to minimize the changes that occur in the coloration of elastomers caused by some types of foods. This process alters the chemical composition of the polymer, inducing a change in its mechanical behavior related to its degradation[20,25]. The focus of this study was to evaluate changes related to the initial force in the first-order movements that depend to a great extent on the ability of the elastics to fix the orthodontic arch inside the bracket slot. In the present study, the null hypothesis that there was no difference between the groups was rejected. As a result, the effect of adding pigment to the orthodontic ligatures made a difference in effectiveness.

From the perspective of the polymer aginng, photodegradation is an important mechanism that it occurs by the absorption of photons of light by the polymer, giving rise to free radicals that result in the splitting of links in the polymer chain and/or crosslinks. These changes result in the degradation of mechanical properties[21,26]. Thus, the commercial packaging of orthodontic elastics must prevent contact with light during storage. According to Saron, the addition of pigments interferes with the photodegradation of polymers. Dark pigments work by absorbing ultraviolet radiation. While the light pigments indirectly reflect the light in the polymer, accelerating the degradation process. In theory, the presence of dark pigments in the composition allows for less photodegradation after manufacture, resulting in higher initial strength[27]. This may be related to the higher strength observed in the present study for gray elastics compared to the crystal elastics in all statistical confrontations.

By the microstructure view, the pigments used for the coloring of the polymers vary according to the size of the particles. Their solubility depends on the interaction between the size of the dye molecules and the polymer mass. The particular characteristics of these materials are related to this interaction, where, being larger, they are capable of absorbing light, allowing the polymers to not lose their properties due to the photodegradation, however they can become abrasive, impairing their use. Dyes with smaller particles become soluble. They have the ability to migrate through the polymeric mass to the surface of the material and this is a disadvantage that can result in color change, sublimation and toxicity[28,29].The presence of dyes in the polymer can anchor the polymeric chains during the linear alignment that occurs when activated by the stretching, resulting in higher initial strength.Thus, it can be suggested that dark colored elastics should have higher initial force due to less photodegradation during storage and due to the anchoring promoted by the presence of the dye during activation. Accordingly, in the present study, gray elastics showed hiegher initial strength than crystal elastics.

It also corroborates the findings of Carvalho et al., who reported that orthodontic elastomeric chains have their performance modified during the stretching, in which the gray elastomeric chains showed hiegher resistance[30].In another study, Martins et al, compared elastics of 16 different colors in a tensile test and found higher initial values for gray compared to crystal, however 
without statistical significance[25-30]. This divergent result may be related to the small number of samples per group (n10) used in this study.However, the presence of dyes in the polymeric mass does not seem to bring only benefits to the final product, its presence affects the degradation properties, such as relaxation. Thus, the color found in orthodontic elastics indicates a higher tendency to relaxation. The polymer, in the presence of moisture such as saliva, has the degradative process accelerated by the generation of a higher amount of free radicals by the polymer with pigments compared to polymers without pigments. This degradation is associated with a color change, so the loss of strength and color change occur simultaneously and in an accelerated way in colored polymers[12,25].The description of these phenomena is associated in agreement with our findings and that of Nakhaei et al., both studies observed higher initial strength for the gray elastics. Nakhaei describes an even higher percentage of loss of force for elastics with higher initial force after 8 weeks of use and color change in all samples associated with degradation[19].

Eliades described that the absorption of lipids during intraoral exposure caused potent structural changes about polyurethanes, acting as calcification nuclei, decreasing the glass transition temperature of the polymer and inducing an early plasticizing effect. However, this process does not seem to be related to the presence or absence of color additives in the polymeric mass[31]. Polymers of different colors are produced by adding different dyes. These dyes can give rise to different interactions and consequently different behaviors in the face of mechanical activation[32]. In a study that evaluated orthodontic elastics of 4 different colors, 2 trademarks and two stretching intensities, different initial strengths and strength loss percentages were observed. Although the pattern of strength reduction over time was similar. Another study with orthodontic elastics of several colors also showed nonstandard results for initial strength and percentage of loss after 24 hours. Again, the pattern of loss of strength over time was the only parameter that presented a pattern for all colors[25].Thus, further studies are needed to understand the behavior of each color pigment and its practical application.In conclusion, the use of crystal ligatures for aesthetic orthodontic treatment is likely to result in less initial tie force in first-order-band activations. A clinical test is suggestive to understand the degradation characteristics of crystal and color orthodontic ligaturures.

\section{Conclusion}

Based on the findings of this study, we can conclude that:

a) The force released by the elastics is directly related to the degree of stretching.

b) The insertion of the gray pigment modified the mechanical behavior in relation to the initial strength, increasing it in all the commercial brands and degrees of stretching evaluated.
The clinical significance of the findings rests on the need to adjust the optimal strength for orthodontic movement with crystal elastics.

\section{References}

1. Baccetti T, Franchi L, Camporesi M (2008) Forces in the Presence of ceramic versus stainless steel brackets with unconventional vs conventional Ligatures. Angle Orthodontist78(1):120-124.

2. Oliveira AS, Kaizer MR, Salgado VE, Soldati DC, Silva RC (2015) Influence of whitening and regular dentifrices on orthodontic clear ligature color stability. J EsthetRestor Dent27(1):S58-S64.

3. Oliveira CB, Maia LGM, SantosPinto A, Gandini Júnior LG(2014)In vitro study of color stability of polycrystalline and monocrystalline ceramic brackets. Dental Press J Orthod19(4):114-121.

4. Silva VD, Lima EMS,Dias C, Osório LB (2016) Analysis of the Influence of Food Colorings. The Open Dentistry Journal10: 516-521.

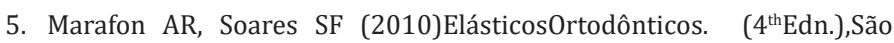
Paulo:Santos.

6. Lam TV, Freer TJ, Brockhurst PJ, Podlich HM (2002) Strength decay of orthodontic elastomeric ligatures. J Orthod29(1):37-43.

7. Harper CA (2002) Handbook of Plastics, Elastomers, and Composites. (4 $4^{\text {th }}$ dn.),New York:The McGraw-Hill Companies.

8. Callister WD, Rethwisch DG (2020) Materials science and engineering: An introduction. (10 ${ }^{\text {th }}$ Edn.), New York: John Wiley \& Sons.

9. Crawford NL, McCarthy C, Murphy TC, Benson PE (2010) Physical properties of conventional and super slick elastomeric ligatures after intraoral use. Angle Orthod80:175-181.

10. Khambay B, Millett D, McHugh S (2004) Evaluation of methods of archwire ligation on frictional resistance. Eur J Orthod 26:327-332.

11. Abrão L, Ortolani CLF, Martins AM, Santana LC (2006) Evaluation in vitro of the intensity of forces liberated by elastic ligatures with and without investment of polymer. Rev Inst CiêncSaúde24(1):31-35.

12. Abdullah MA, Sahal AA, Mohammed SM, Khalid AA (2015) Color stability and force decay of clear orthodontic elastomeric chains: An in vitro study. International Orthodontics13: 287-301.

13. Brantley WA, Eliades T (2001) Orthodontic materials: scientific and clinical aspects. Am J Orthod Dentofacial Orthop 119:672-673.

14. Buchmann N, Senn C, Ball J, Brauchli L (2012) Influence of initial strain on the force decay of currently avaible elastic chains over time. Angle Orthod82(3): 529-535.

15. Behnaz M, Namvar F, Sohrabi S, Parishanian M (2018) Effect of Bleaching Mouthwash on Force Decay of Orthodontic Elastomeric Chains. J Contemp Dent Pract19(2):221-225.

16. Ardeshna AP, Vaidyanathan TK (2009)Colour changes of orthodontic elastomeric module materials exposed to in vitro dietary media. J Orthod36(3):177-185.

17. Silva AVM, Mattos GV, Kato CM, Normando D (2012) In vivo color changes of esthetic orthodontic ligatures. Dental Press J Orthod 17(5):76-80.

18. Loriato LB, Machado AW, Pacheco W (2006) Clinical and biomechanical aspects of elastics in Orthodontics. R Clin Ortodon Dental Press 5:144157.

19. Nakhaei S, Agahi RH, Aminian A, Razaeizadeh M (2017) Discoloration and force degradation of orthodontic elastomeric ligatures. Dental Press J Orthod22(2):45-54.

20. Kawabata E, Dantas VL, Kato CB, Normando D (2016) Color changes of esthetic orthodontic ligatures evaluated by orthodontists and patients: a clinical study. Dental Press J Orthod21(5):53-57. 
21. Guimarães GS, Morais LS, Souza MMG, Elias CN (2013) Superficial morphology and mechanical properties and of in vivo aged orthodontic ligatures. Dental Press J Orthod18(3):107-112.

22. Braga E, Souza G, Barretto P, Ferraz C, Pithon M (2019) Experimental Evaluation of Strength Degradation of Orthodontic Chain Elastics Immersed in Hot Beverages. Journal of Indian Orthodontic Society 53(4): 244-248.

23. Yagura D, Baggio PE, Carreiro LS, Takahashi R (2013) Deformation of elastomeric chains related to the amount and time of stretching. Dental Press J Orthod18(3):136-142.

24. Motta AFJ (2011) Cury-Saramago AA, Nojima LI. In vitro evaluation of force delivered by elastomeric chains. Dental Press J Orthod16(6):36-37.

25. Martins MM, Mendes AM, Almeida MAO, Goldner MTA, Ramos VF (2006) Comparative study of different colors of molded elastomeric ligatures. Rev Dental Press OrtodOrtop Facial. jul-ago11:81-90.

26. Rabek JF (2012) Polymer photodegradation: mechanisms and experimental methods ( $2^{\text {nd }} E d n$. $)$, New York. Spring.

\section{ISSN: 2574-1241}

DOI: $10.26717 / B J S T R .2020 .30 .004916$

Glaucio Serra Guimarães. Biomed J Sci \& Tech Res

CC (i) This work is licensed under Creative

Submission Link: https://biomedres.us/submit-manuscript.php
27. Saron C, Felisberti MI (2006) Influence of colorants on the degradation and stabilization of polymers. Química Nova29(1):124-128.

28. Allen NS, Pena JM, Edge M, Liauw CM (2000) Behaviour of carbon black pigments as excited state quenchers in LDPE. Polym. Degrad. Stab67(3):563-566.

29. Henriques JFC, Hayasaki SM, Henriques RP (2003) Orthodontic elastics: How to select them to obtain the best effectiveness. JornalBrasileiro de OrtodontiaOrtopedia Facial8(48): 471-475

30. Carvalho RS, Almeida RC, Almeida MHC, Gumieiro EH (2003) The use of elastomeric chains in Orthodontics. R. Paulista de Odontologia25(4): 25-29.

31. Eliades T, Bourauel C (2005) Intraoral aging of orthodontic materials: the picture we miss and its clinical relevance. Am J Orthod Dentofacial Orthop127(4):403-412.

32. Macêdo EOD, Collares FM, Leitune VCB, Samuel SMW, Fortes CBB (2012) Pigment effect on the long-term elasticity of elastomeric ligatures. Dental Press J Orthod17(3):27-28.

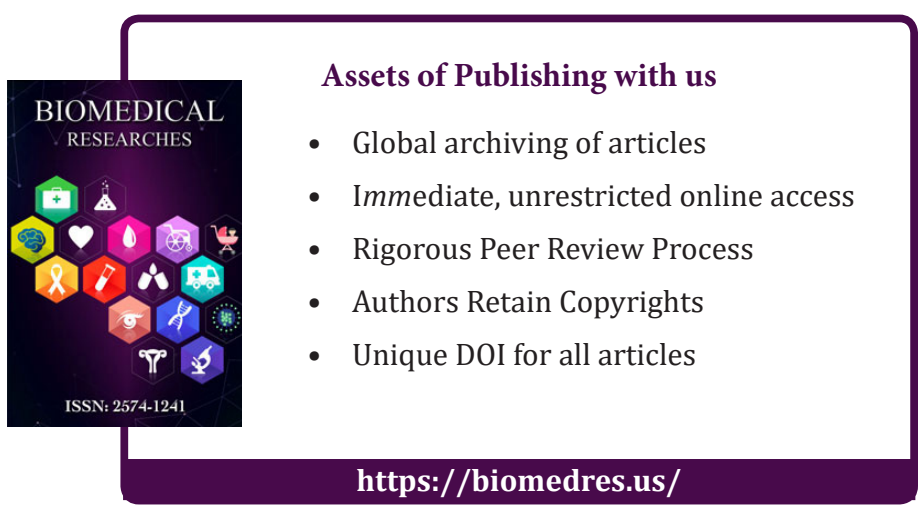

